\title{
PRÁTICAS ARTÍSTICAS NAS ESCOLAS DO CAMPO: UMA FORMA DE LINGUAGEM PARA LER E INTERPRETAR O MUNDO
}

\author{
ARTISTIC PRACTICES IN RURAL SCHOOLS: A WAY OF LANGUAGE TO READ AND \\ UNDERSTAND THE WORLD
}

\author{
Cristiene Adriana da Silva Carvalho ${ }^{1}$ \\ Maria Isabel Antunes-Rocha ${ }^{2}$
}

\begin{abstract}
Resumo: Este texto analisa os movimentos de reelaboração das Representações Sociais dos professores do campo, egressos do curso de Licenciatura em Educação do Campo da Faculdade de Educação da Universidade Federal de Minas Gerais sobre as práticas artísticas. Partimos da compreensão das práticas artísticas como formas de criação, fruição e reflexão da Arte nos processos educativos que carregam historicidade e resistência presentes do Movimento de luta pela Educação do Campo. Este estudo teve como referencial a perspectiva das Representações Sociais em Movimento vinculada à Teoria das Representações Sociais. A abordagem metodológica utilizou como procedimentos entrevistas narrativas e observação das práticas pedagógicas. A análise dos dados foi realizada a partir da reconstrução das trajetórias, levandose em conta as movimentações das representações sobre as práticas artísticas, que passam a ser vistas como mecanismos pedagógicos de luta por uma educação transformadora e pelo fortalecimento da identidade campesina.
\end{abstract}

Palavras-chave: Práticas artísticas; Educação do Campo; representações sociais.

\begin{abstract}
This paper analyzes the movement of re-elaboration of social representations on artistic practices of rural teachers that Undergraduate in the teaching course of rural education from the Faculdade de Educação of the Universidade Federal de Minas Gerais. We understand the artistic practices as a way of creation, fruition, and reflection of art present in the educative processes. Those practices carry historicity and resistance embedded in the struggle of social movements to the right of rural education. The theoretical background is guided by the Social Representations in Movement, related to the Theory of Social Representations. The methodological approach is based on narrative interviews and observations of pedagogic practices. The data analysis was made from the reconstruction of trajectories considering the movement of the Social Representations. We observed that the artistic practices can be seeing as a pedagogical mechanism of the struggle for transforming education.
\end{abstract}

Keywords: Artistic practices; Rural Education; social representations.

\section{Introdução}

Este texto traz reflexões a respeito das práticas artísticas nas escolas do campo, na busca de entendê-las como uma forma de linguagem que lê e interpreta o mundo. Compreendemos como práticas artísticas o conjunto de linguagens artísticas construídas e fruídas pelos sujeitos, cujo entendimento abarca as relações sociais. Ao utilizar tal termo, incorporamos o conjunto de linguagens o qual denominamos de Artes e buscamos evidenciar a dimensão do trabalho humano historicamente presente no campo artístico.

\footnotetext{
${ }^{1}$ Universidade Federal de Minas Gerais, Belo Horizonte, MG, Brasil.

${ }^{2}$ Universidade Federal de Minas Gerais, Belo Horizonte, MG, Brasil.
} 
Em função da produção em uma sociedade organizada por meio da disputa da posse e uso dos bens materiais e simbólicos, vai emergindo, ao longo da história, pelo menos duas tensões no campo das práticas artísticas. Tais tensões podem ser visualizadas segundo dois conjuntos dicotômicos: práticas artísticas neutras ou engajadas e práticas artísticas eruditas ou populares. Buscamos, neste trabalho, realizar a leitura de tais tensões a partir de uma perspectiva dialética, a fim de superar a dicotomia assente na compreensão das relações de complementaridade e diálogo destas.

Quando abordamos as tensões na educação escolar, observa-se a presença de pelo menos mais dois conjuntos dicotômicos. Trata-se da tensão entre as práticas artísticas como produção de conhecimento ou entretenimento e das práticas artísticas compreendidas a partir da técnica ou didatizadas. Estas dicotomias imprimem no trabalho docente a necessidade de conduzir processos de ensino e aprendizagem que promovam a leitura da obra de Arte em diálogo com sua contextualização histórica, social e estética, construindo-se, dessa forma, uma formação e fruição aguçadoras de sentidos e significados.

Ao trazermos o debate das práticas artísticas para o contexto da escola do campo, incorporamos as discussões presentes no Movimento da Educação do Campo, que vem, há mais de 20 anos, organizando-se coletivamente em busca do direito à escola. Esse movimento reivindicou a construção de políticas públicas para a formação de professores, o que resultou na criação de programas de formação inicial e continuada de professores, que trazem para a escola o protagonismo da luta pela terra. As práticas artísticas construídas nesse contexto são desafiadas a incorporar tal debate e agregar os sentidos da luta por direitos, bem como de resistência para a preservação dos valores culturais, a exemplo da luta pela preservação das práticas folclóricas tradicionais. A tradução desses tensionamentos na prática dos educadores do campo ocorre a partir do desafio em lidar com as dicotomias em uma prática comprometida com a transformação da escola, do campo e da sociedade.

Para produzir este artigo nos ancoramos no trabalho de Carvalho (2017) que teve como objetivo evidenciar e analisar os desafios vivenciados por esses educadores no processo de formação e prática docente, a partir do enfoque das práticas artísticas. A questão que motivou tal processo de pesquisa centrou-se na análise do que acontece quando os professores do campo, egressos do Curso de Licenciatura em Educação do Campo desenvolvido na Faculdade de Educação da Universidade Federal de Minas Gerais (LECampo/FaE/UFMG), começam a atuar enquanto docentes e desenvolvem suas práticas artísticas e pedagógicas nas escolas do campo. Analisamos o processo de construção das Representações Sociais das práticas artísticas e pedagógicas desses sujeitos. Essas representações carregam os conteúdos apreendidos na universidade ou são construídas a partir de elementos presentes nas demandas escolares incorporando também características culturais marcantes da identidade camponesa?

Partimos da hipótese de que as práticas artísticas dos professores do campo foram marcadas pela tentativa de estabelecer diálogo entre o conteúdo acadêmico de sua formação e a afirmação de sua identidade do campo e ainda incorpora os elementos de reflexão, fruição e construção artística. Esse diálogo era permeado por um movimento de construção e reelaboração das suas Representações Sociais, caracterizado por diferentes posicionamentos diante das práticas artísticas, analisadas a partir da perspectiva teórico-metodológica das Representações Sociais em Movimento.

Sendo assim, este artigo apresenta os resultados da pesquisa realizada junto a 2 egressos da LECampo/FaE/UFMG, aqui apresentados sob os pseudônimos Camila e Lucas. Os sujeitos haviam cursado a habilitação em Língua, Arte e Literatura (LAL), tendo ingressado no curso no ano de 2010 e finalizado no ano de 2015. A escolha de tais sujeitos diz respeito à tentativa de dar continuidade à pesquisa de Carvalho (2015), que analisava as práticas artísticas durante a formação na LECampo/FaE/UFMG, em busca de perceber a relação existente entre a formação e a prática docente. 
A realização de um trabalho a respeito dessa temática justificou-se considerando a importância de se construir reflexões sobre o processo de formação e atuação dos professores do campo, especialmente no que se refere às suas práticas artísticas. Foi também justificado pela necessidade em aprofundarmos o debate sobre a formação de professores nos cursos de Licenciaturas em Educação do Campo no Brasil, hoje presentes em mais de 43 instituições, bem como de compreender o contexto de atuação dos egressos desses cursos, em diálogo com os tensionamentos presentes nas escolas do campo.

A coleta de dados ocorreu no ano de 2016 nos municípios de Jordânia e Rubim, localizados na região do Vale do Jequitinhonha, Minas Gerais. Foram realizadas entrevistas narrativas associadas à observação das práticas dos sujeitos, tomando como referência os pressupostos de Jovchelovitch e Bauer (2013). A entrevista narrativa possibilitou-nos apreender os elementos sobre a vida dos sujeitos, suas escolhas para a construção de práticas pedagógicas e reflexões a respeito das práticas artísticas. A análise da prática pedagógica colocou-nos diante da integração entre as ações educativas, sociais, políticas e familiares do professor, elementos que deram pano de fundo para compreender suas ações.

Para tanto, elaboramos um texto apresentando, inicialmente, as referências que orientaram os caminhos teóricos e metodológicos da pesquisa. Em seguida, apresentamos as trajetórias de formação e prática pedagógica dos professores do campo, o que permitiu analisar as Representações Sociais em movimento para trazer as considerações conclusivas.

\section{Referências teóricas e metodológicas}

Para esta pesquisa tivemos como referência conceitos pertencentes ao campo da Teoria das Representações Sociais, Artes e Educação do Campo. Entendemos que a articulação de tais conceitos permitiria um olhar psicossocial sobre os sujeitos, englobando também o contexto e as práticas pedagógicas e artísticas desenvolvidas por eles.

Buscamos em Moscovici (1978) a compreensão das Representações Sociais como formas de conhecimento socialmente partilhadas, elaboradas a partir de situações novas, vivenciadas pelo sujeito. A Teoria das Representações Sociais (TRS), que analisa as formas de pensar, sentir e agir dos sujeitos a partir de uma abordagem psicossocial, permitiu o estudo dos processos que unem a dimensão cognitiva do indivíduo, compreendendo as suas ações, motivações e sentimentos. Para compreendermos o processo de elaboração das Representações Sociais nos referenciamos na abordagem processual das Representações Sociais proposta por Jodelet (2001) que nos possibilitou apreender os processos constitutivos da representação em uma análise histórico-dialética.

Partimos da perspectiva das Representações Sociais em Movimento (RSM), proposta por Antunes-Rocha (2012), para a percepção do movimento nas Representações Sociais de sujeitos que se encontram em contextos geradores de mudança. A perspectiva RSM permite a compreensão dos elementos que desestabilizam as representações consolidadas e provocam os sujeitos a alterarem suas formas de pensar, sentir e agir. Antunes-Rocha (et al., 2015) compreendem que o movimento representacional ocorre a partir da transformação ocorrida nas formas de pensar, sentir e agir do sujeito em relação a uma situação estranha/nova, em busca de torná-la familiar. Para os autores, o movimento de construção das Representações Sociais é marcado por três perspectivas: a primeira delas: o sujeito diante do objeto estranho abandona o conhecido e vive totalmente o novo; a segunda delas: é marcada pela negação do novo; e a terceira delas: é marcada pela aceitação do novo sem desprezar o conhecido.

Para a compreensão das práticas artísticas em diálogo com as transformações sociais, recorremos a Bosi (1986) e a Pareyson (1954) que nos permitem apreender o processo artístico a partir das 3 vias: fazer, conhecer e exprimir. A primeira via de reflexão artística definida por Bosi 
(1986) permite compreender a transformação dos signos e objetos da natureza em elementos da cultura a partir do fazer artístico. A segunda representa a leitura da obra a partir de sua interpretação como objeto de conhecimento e construção histórica. Já a terceira via, caracteriza-se pela expressão de signos e símbolos a partir das intencionalidades e contextos de criação, considerando a dialética de forma e força na fronteira da identidade do artista. Tais perspectivas ofereceram um olhar para as dimensões de leitura e complementaridade dos processos do ensino de Artes.

Dentro da especificidade do cenário educacional, recorremos à Barbosa (2008) e, especificamente, à metodologia da abordagem triangular que possibilita a compreensão das práticas artísticas no cenário pedagógico a partir das ações: contextualização, concepção, criação e leitura da obra de arte. Tal abordagem foi fundamental para pensar nas múltiplas dimensões para entendimento do tensionamento das práticas artísticas como produção de conhecimento ou entretenimento e das práticas artísticas compreendidas a partir da técnica ou didatizadas. Ao pensarmos a diversidade das práticas artísticas na escola do campo, recorremos à Abordagem Espiral, proposta por Machado (2012), para a interpretação do conhecimento artístico em forma espiral, articulando diversas linguagens e metodologias em poéticas artísticas marcadas pela miscigenação. Tal abordagem permitiu analisar a complementaridade das práticas eruditas e populares, bem como a dinamicidade das transformações artísticas na sociedade.

A Educação do Campo foi compreendida nesta pesquisa para além do contexto de estudo, uma vez que forneceu elementos conceituais para compreender as intencionalidades do processo de formação e prática dos professores. Para isso, buscamos em Caldart (2003) a construção de elementos históricos e das políticas públicas em Educação do Campo que nos permitiram dialogar com os princípios da Educação do Campo, enquanto categoria analítica das práticas artísticas dos sujeitos do Campo. Ancoramo-nos, especificamente, nos princípios protagonismo da luta e escola de direito para compreender os sujeitos analisados como parte de um coletivo que vem construindo um paradigma contra-hegemônico que permite a compreensão das relações entre campo e cidade.

A partir de tais referências, construímos as categorias analíticas que permitiram observar o que acontece quando os professores do campo começam a atuar como docentes. A perspectiva teórico-metodológica das Representações Sociais em Movimento foi fundamental para analisar os elementos constitutivos do movimento de construção das Representações Sociais dos sujeitos. Tal perspectiva permitiu reconstruir as trajetórias dos sujeitos em tempos e espaços de escolarização, formação na universidade e inserção na docência. Tal referencial auxiliou na análise do movimento das formas de pensar, sentir e agir dos egressos da LECampo/FaE/UFMG sobre as práticas artísticas, considerando a inserção no ambiente acadêmico como um espaço/tempo provocador de alterações em seus saberes.

De posse disso, recorremos às vias de construção das práticas artísticas para compreender as características atribuídas a elas que foram desenvolvidas pelos sujeitos, percebendo-se ainda, nesse movimento, as especificidades em relação ao cenário educativo.

Os referenciais teóricos pertencentes à Educação do Campo foram fundamentais para que compreendêssemos as especificidades de protagonismo e escola de direito presentes nas práticas artísticas e pedagógicas dos professores do campo.

\section{Representações em movimento}

O processo de apreensão do movimento das Representações Sociais iniciou-se a partir da reconstrução das trajetórias de vida dos sujeitos. Tal passo analítico permitiu que compreendêssemos o contexto de escolarização, participação em atividades artísticas e 
culturais, trajetória de formação universitária e percurso profissional, o que nos permitiu visualizar o movimento das práticas artísticas em movimentos significativos de reelaboração.

A educadora Camila tem 35 anos e nasceu no município de Rubim, sendo a terceira filha de um casal de trabalhadores do Campo. Casada e mãe de dois filhos, após se formar na LECampo/FaE/UFMG foi aprovada no concurso para professora do Ensino Fundamental da rede estadual em Rubim. Além disso, também atuava como auxiliar de secretaria no contraturno e como tutora de um curso de Educação à distância. Articuladas a essas atividades, no momento da coleta de dados, Camila também cursava o mestrado em Educação do Campo oferecido em alternância.

A trajetória de Camila é marcada pela ausência de experiências artísticas em sua escolarização. Na infância, morando com a família, na fazenda em que o pai trabalhava, o contato com as práticas artísticas foi limitado. Para poder prosseguir os estudos no Ensino Fundamental foi necessário mudarse para a sede do município e articular o trabalho aos estudos. Apesar do sonho de cursar uma universidade, as circunstâncias colocavam os estudos em uma perspectiva distante. Até que no ano de 2009 recebeu, através de uma amiga, o edital de vestibular para a LECampo/FaE/UFMG. O interesse no curso veio, principalmente, pelo fato de ele possibilitar a formação em alternância, que garantiria a continuidade no seu trabalho e o acompanhamento dos filhos.

A formação na LECampo/FaE/UFMG permitiu que Camila tivesse contato com elementos artísticos de natureza cênica, musical, plástica e literária e obtivesse chaves para análise da sociedade. Esse contato possibilitou-a reconhecer as manifestações culturais populares de seu município, enquanto práticas artísticas. Tal reconhecimento inspirou-a na construção do projeto de estágio de artes com a temática da manifestação cultural Boi de Janeiro, com o objetivo de promover o reconhecimento de valor artístico, cultural e histórico de uma prática do município.

A análise das práticas artísticas e pedagógicas de Camila, enquanto professora, permitenos perceber uma ação docente pautada na perspectiva interdisciplinar que dialoga com a dimensão de diversidade de linguagens artísticas aprendidas na formação na Universidade. Ela revela uma postura de resistência no processo de construção da expressividade artística que materializa o sentido de sua luta pelo direito à educação, incluindo-se aí o direito à arte na educação como perspectiva de formação participativa do sujeito.

O educador Lucas tem 26 anos e nasceu no município de Jordânia, sendo o terceiro filho de uma família de trabalhadores do campo. Até os dez anos ele viveu na fazenda onde o pai trabalhava, sendo necessário cumprir um percurso de quase 4 horas diárias de deslocamento até a escola. O contato com as primeiras práticas artísticas foi marcado pelo envolvimento com o Festival de Folclore de Jordânia. Sua participação em espetáculos de dança e teatro possibilitou contato com temáticas voltadas à cultura popular que se configurara como um elemento da sua identidade. Outro elemento fundamental para a trajetória de Lucas deu-se a partir da filiação e trabalho como mobilizador junto ao Sindicato de Trabalhadores Rurais de Jordânia. A inserção no sindicato possibilitou o acesso à divulgação sobre o vestibular na LECampo/FaE/UFMG.

A formação de Lucas na Universidade possibilitou a construção de conhecimento, na perspectiva da docência. Conhecer as manifestações eruditas, bem como as formas de ensinálas em diálogo com as populares, foi importante para que ele pudesse pensar sobre a não hierarquização do conhecimento nas manifestações de seu município. Em seu estágio de Artes, Lucas considerou a perspectiva de diálogo entre os saberes eruditos e populares, abordando a temática das técnicas teatrais para o Festival de Folclore, a fim de refletir, junto aos alunos, sobre a não hierarquização das manifestações artísticas.

Após a sua formação na LECampo/FaE/UFMG, Lucas foi aprovado no concurso para o cargo de professor da Educação Básica do Estado de Minas Gerais, ministrando aulas para o segundo ciclo do Ensino Fundamental e Ensino Médio. Seu cargo direcionado, inicialmente, para a área de de Língua Portuguesa permite-lhe fazer inserções de temáticas sobre a Literatura 
e Arte e promover uma formação interdisciplinar. Notamos nas práticas pedagógicas de Lucas destaque para os elementos da cultura popular. Tais práticas de ensino provocam os alunos a posicionarem-se sobre as manifestações artísticas presentes no município e na sociedade.

Neste trabalho, ao olharmos para o movimento de Camila e Lucas, analisamos como os momentos de formação na LECampo/FaE/UFMG e de inserção na docência desestabilizaram as suas representações sobre as práticas artísticas, buscando apreender qual o processo de posicionamento adotado para lidar com o elemento novo, formação e docência, em seu universo representacional. Buscamos apreender quais os conteúdos presentes nesse processo de movimentação das formas de pensar, sentir e agir, a partir da dimensão da totalidade das práticas artísticas, buscando notar os aspectos sociais, históricos, políticos e contextuais.

O movimento de construção das Representações Sociais de Camila e Lucas pode ser visualizado a partir da imagem em espiral a seguir, que sintetiza os elementos presentes em suas Representações Sociais. A partir do que Antunes-Rocha (2012) fala a respeito das Representações Sociais na perspectiva do Movimento, construímos quatro posicionamentos: saberes prévios, práticas artísticas na graduação, estágio e práticas artísticas nas práticas pedagógicas.

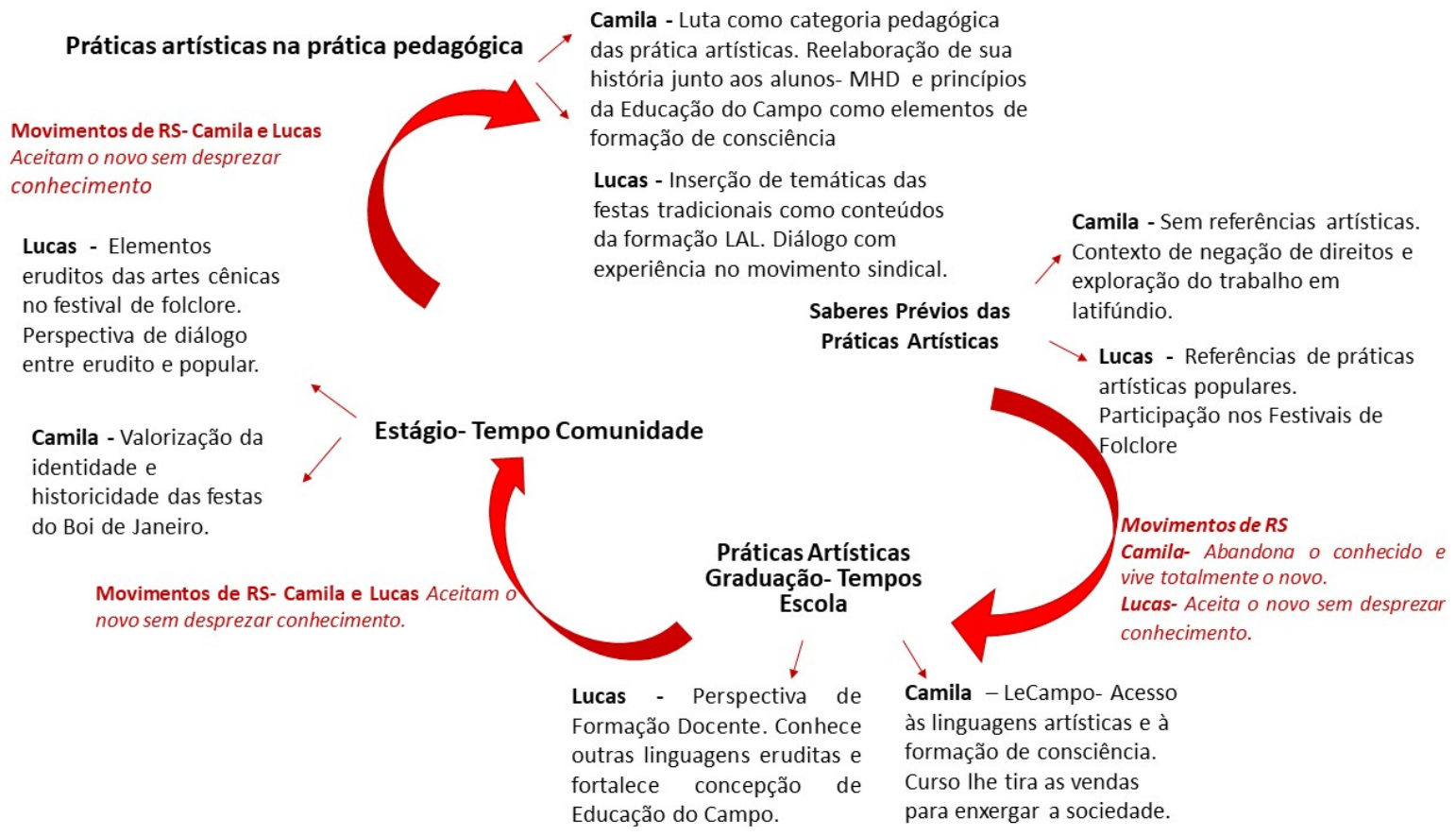

Figura 01: Movimentos de construção da RS Camila e Lucas. Fonte (Carvalho, 2018, p. 322)

A análise do primeiro posicionamento, "saberes prévios", ilustra a chegada a LECampo/FaE/UFMG e demonstra como Camila e Lucas operacionalizaram a bagagem cultural das práticas artísticas obtidas na infância e adolescência. Os saberes prévios de Camila, ao chegar no curso, são marcados pela ausência de experiências artísticas em seu cotidiano durante sua infância e adolescência. Já os saberes prévios de Lucas traziam representações ancoradas em referências populares em torno de sua experiência com os festivais de folclore.

$\mathrm{O}$ acesso à informação durante a graduação em Educação do Campo foi responsável pelo primeiro momento de desestabilização das Representações Sociais dos sujeitos, o que pode ser visualizado no segundo posicionamento "práticas artísticas graduação". Para Camila, a experiência da graduação modificou sua forma de pensar a arte e de agir de forma mais crítica em relação às questões sociais. Para ela, o curso foi a oportunidade de acessar informações e modificar a perspectiva da falta de referências com as práticas artísticas. Abandonar o 
conhecido e viver algo novo possibilitou que Camila compreendesse a arte em seu município e o seu papel enquanto agente de luta pela educação. Para Lucas, aprender teorias no curso foi uma forma de organizar suas futuras práticas docentes. Nesse sentido, o movimento de construção de sua representação social foi realizado agregando a formação docente aos conhecimentos sobre práticas artísticas populares de seu município.

A prática do estágio de artes, que marca o terceiro posicionamento, foi o primeiro contato dos sujeitos com a docência e representou a possibilidade de organização de suas práticas pedagógicas, a partir da formação na LeCampo. O projeto de estágio de Camila priorizou temáticas relacionadas ao "Boi de Janeiro" de conteúdo popular. Esse movimento de valorizálo, enquanto manifestação artística, realizado por ela durante a formação da LECampo/FaE/UFMG, mostra que o estágio possibilitou a reafirmação de uma representação social das práticas artísticas conhecidas durante o curso de Licenciatura em Educação do Campo. Já o projeto de estágio de Lucas levou em consideração a perspectiva dos saberes eruditos das artes cênicas em diálogo com o "Festival Popular de Folclore". Notamos que sua trajetória de construção das Representações Sociais sobre as práticas artísticas revela a presença da terceira perspectiva, apontada por Antunes-Rocha (et al., 2015), segundo a qual ele aceitou o novo, sem desprezar o conhecimento construído anteriormente.

O quarto posicionamento de Camila e Lucas caracteriza a inserção da ação docente e um contato aprofundado com as práticas artísticas na prática pedagógica. Para isso, resgatamos o que Antunes-Rocha (et al., 2015) ensina sobre o movimento que os sujeitos realizam diante de uma situação nova. Camila e Lucas foram os primeiros docentes formados na LECampo/FaE/UFMG na habilitação em Língua, Arte e Literatura a serem aprovados em concursos públicos e atuarem nas escolas de seus municípios. Isto demanda que eles, a todo o momento, reafirmem a capacidade para atuação e ainda busquem inserir discussões sobre a Educação do Campo.

Para apreender o movimento realizado por Camila, após sua inserção profissional na docência, consideramos a mudança em diálogo com os conhecimentos anteriores, o elemento chave de seu processo de construção das Representações Sociais. O movimento de resistência presente em suas Representações Sociais é, para Camila, fundamental para a compreensão da Arte e das transformações que esse campo do conhecimento pode trazer para a formação dos alunos. É essa resistência que permite que ela veja na Arte a perspectiva de expressão de luta.

Eu venho me formando cada dia, buscando me inteirar e resistindo. Eu hoje vejo a arte como forma de expressão de resistir à escola. Porque nada na escola é feito para valorizar e ter a arte como direito, a literatura como direito e a forma de expressão. Então hoje trabalhar é uma forma de resistir. Minha relação da arte como forma de expressão foi a forma que eu passei a ver a arte. O que é produzir a arte e ter a arte para a pessoa se expressar. Arte é se livrar dessas amarras que ficam. É isso que eu venho tentando fazer. (Camila)

Ao analisarmos o movimento de construção das Representações Sociais sobre as Práticas Artísticas, nas práticas pedagógicas do educador Lucas, percebemos que ele é marcado pela tentativa constante de articulação entre elementos eruditos e populares. $\mathrm{O}$ diálogo entre as manifestações eruditas e populares é uma marca identitária na prática artística desenvolvida por ele em sala de aula. Notamos que, ao se preocupar com a transformação das linguagens tradicionais, Lucas instiga os alunos a buscarem a identificação com as referências culturais e a expressarem-se em diversas linguagens artísticas. 
É um desafio muito grande. Não quero destruir ou demonizar os conceitos e os tipos de arte consagrados e canônicos, mas alargar e passear entre as artes. Eu posso muito bem admirar uma obra, um quadro, mas eu posso também admirar um cordel de Patativa do Assaré, uma xilogravura ou eu posso ir lá na roça e ver o cara fazendo um balaio diferente e colocando isso de forma artística. Existe uma vantagem de se alargar o conceito de arte porque a vida se torna mais prazerosa. Mas é um desafio muito grande despertar isso nos alunos também despertar. $\mathrm{E}$ também pela dimensão mais política, não apenas pelo conceito de arte do prazer, mas uma arte que ela é política, ela não é neutra, ela é feita do povo para o povo. Não é algo feito por poucos e admirado por muitos. Talvez seja uma coisa que é feita por muitos e compartilhado por outros tantos. Essa troca de saberes essa troca artística é muito importante. (Lucas).

Foi necessário que Camila e Lucas aceitassem a nova condição de professores na escola, adaptando ao conteúdo da área de Língua, Arte e Literatura, o método e as elaborações teóricas, apreendidos durante a formação na graduação. A tarefa de inserção da Educação do Campo no meio escolar é o principal desafio dessa familiaridade. Ambos os educadores são vistos como pioneiros, ao construir práticas e trazer ao corpo docente e pedagógico reflexões sobre o papel da escola do Campo e a possibilidade dela transformar a realidade dos sujeitos do Campo.

\section{Considerações conclusivas}

No exercício que nos compete tecer considerações sobre esta temática, pudemos perceber os desafios enfrentados por esses professores do Campo diante dos tensionamentos presentes nas escolas, verificando que as Representações Sociais sobre as práticas artísticas revelam a presença de elementos identitários e de luta pela transformação do campo em diálogo com os conteúdos apreendidos durante a formação na LECampo/FaE/UFMG.

A reconstrução das trajetórias de escolarização, formação, estágio e docência de Camila e Lucas permitiu-nos aproximar dos elementos que instigaram os sujeitos a mudar seus posicionamentos no processo de reelaboração de suas Representações Sociais sobre as práticas artísticas.

Analisando a síntese dos movimentos de construção das Representações Sociais de Camila e Lucas, podemos apreender que os posicionamentos realizados em cada movimento contêm um somatório de questões socioculturais que tangenciaram as Representações Sociais dos educadores sobre as suas práticas artísticas e pedagógicas.

Ao trazermos a análise das Representações Sociais desses sujeitos, compreendemos que ele e ela trazem consigo a elaboração social construída junto aos seus pares na formação da LECampo/FaE/UFMG e também o contexto da categoria docente nas escolas do Campo. Para tal, realizam também um diálogo com os elementos históricos, sociais e os desafios concretos enfrentados em sua ação docente, no que se refere às práticas artísticas.

A partir das Representações Sociais em Movimento, pudemos perceber que Camila e Lucas partilham, em comum, o conhecimento e a técnica apreendidos na formação da LECampo/FaE/UFMG, operacionalizando tal representação nas práticas artísticas e pedagógicas desenvolvidas por eles enquanto docentes. Percebemos que o processo de construção das Representações Sociais de Camila e Lucas sobre as práticas artísticas, enquanto docentes, é marcado pela terceira perspectiva das Representações Sociais em movimento, o que, segundo Antunes-Rocha (et al., 2015), caracteriza-se pela mudança diante de uma situação nova, onde os sujeitos aceitam o novo, sem desprezar o conhecido. Um fato que nos chama a atenção é que, embora ambos tenham sido alocados nesse movimento, a trajetória percorrida 
por cada um é marcada por particularidades, contudo notamos que tais elementos relacionamse a uma dinâmica coletiva do contexto histórico, político e social dos sujeitos do Campo.

Pudemos perceber que as práticas artísticas de Camila e Lucas partem da perspectiva de formação do conhecimento, integrando Língua, Arte e Literatura, associando em suas práticas a perspectiva de transformação social. Ambos os educadores promovem discussões com temáticas sobre a reforma agrária, o trabalho dos sujeitos do Campo e a desigualdade social. A inserção desses temas aparece como reflexo da formação em um curso de graduação que nasceu da luta dos movimentos sociais e, desse modo, promove, em suas práticas de ensino, reflexões, sobre as perspectivas de mudança da sociedade.

Percebemos que o pioneirismo desses sujeitos provoca-os a construir uma escola do campo, a partir das ações desenvolvidas em suas salas de aula. Para isso, notamos que Camila apega-se à formação na LECampo/FaE/UFMG, em diálogo com suas experiências de vida, superação de opressões e os novos aprendizados no mestrado. Já Lucas, apega-se ao conteúdo da graduação, em diálogo com a formação no movimento sindical. Em ambos notamos a inserção da formação, um interesse comum, com elementos desafiadores de suas tarefas docentes concretas. Moscovici (1978), ao falar sobre os modos de vida e os sentidos construídos nas representações, ajuda-nos a entender a partilha e operacionalização do conhecimento e crença como um interesse comum dos sujeitos.

É possível perceber ainda o uso da Arte enquanto prática, vista a partir da construção de práticas pedagógicas que remetem à história dos municípios. Percebemos que, nesse movimento, os sujeitos promovem a construção de um processo de educação do olhar, promovendo processos que articulam elementos das convenções literárias das narrativas, dos elementos da cultura local, bem como da memória e história do município. Isso significa o resgate de conhecimentos que remetem ao fortalecimento da identidade a partir das trajetórias pessoais e familiares dos estudantes.

\section{Referências}

ANTUNES-ROCHA. M I. Da cor da terra: Representações Sociais de professores sobre os alunos no contexto da luta pela terra. Belo Horizonte: Editora UFMG, 2012.

ANTUNES-ROCHA. M. I.; AMORIM, K. O.; BENFICA, W. A.; CARVALHO, C. A. S.; RIBEIRO, L. P. Representações sociais em movimento: desafios para tornar o estranho em familiar. In: XII CONGRESSO NACIONAL DE PSICOLOGIA ESCOLAR E EDUCACIONAL, 2015, São Paulo. Livro de Trabalhos Completos... São Paulo: ABRAPEE, 2015.

BARBOSA, A. M. (Org.). Inquietações e mudanças no ensino da arte. São Paulo: Cortez, 2008.

BOSI, A. Reflexões sobre arte. São Paulo: Editora Ática, 1986.

CALDART, R. S. A Escola do Campo em Movimento. Currículo sem Fronteiras, v. 3, n. 1, p. 60-81, jan./jun. 2003. ISSN 1645-1384. Disponível em: http://www.curriculosemfronteiras.org.

CARVALHO, C. A. S. 2015. Práticas artísticas dos estudantes do curso de licenciatura em Educação do Campo: um estudo na perspectiva das Representações Sociais. Dissertação (Mestrado em Educação) - Faculdade de Educação, Programa de Pós-Graduação em Educação: Conhecimento e Inclusão Social, Universidade Federal de Minas Gerais, Belo Horizonte, 2015. 
CARVALHO, C. A. S. 2017. Representações Sociais das práticas artísticas na atuação de professores do campo. Tese (Doutorado em Educação) - Faculdade de Educação, Programa de Pós-Graduação em Educação: Conhecimento e Inclusão Social, Universidade Federal de Minas Gerais, Belo Horizonte, 2017.

CARVALHO, C. A. S. Representações sociais das práticas artísticas na formação e atuação de professores do Campo. Curitiba: APPRIS, 2018.

JODELET, D. Representações Sociais: um domínio em expansão. In. JODELET, D. (Org.). As Representações Sociais. Rio de Janeiro: UERJ, 2001.

JOVCHELOVITCH, S.; BAUER M.; A Entrevista Narrativa. In: GASKELL, G.; BAUER, M. W. Pesquisa qualitativa com texto, imagem e som: um manual prático. 11. ed. Petrópolis: Vozes, 2013.

MACHADO, M. M. Fazer surgir antiestruturas: abordagem espiral para um currículo em artes. Revista e-curriculum, São Paulo, v. 8, abril, 2012.

MOSCOVICI, S. A representação social da psicanálise. Tradução de Cabral. Rio de Janeiro: Zahar, 1978.

PAREYSON, L. Estética. Teoria dela formatività. Turim: Ed. Filosofia, 1954.

\section{Sobre as autoras}

Cristiene Adriana da Silva Carvalho é graduada em Artes Cênicas pela Universidade Federal de Ouro Preto e graduada em Pedagogia pela Universidade de Uberaba, tem mestrado e doutorado em Educação pela Universidade Federal de Minas Gerais. É pesquisadora do Núcleo de Estudos e Pesquisas em Educação do Campo e do Grupo de Estudos em Representações Sociais da Faculdade de Educação da Universidade Federal de Minas Gerais. Realiza pesquisas nas áreas de: Arte, práticas artísticas, Educação do Campo, formação e prática docente e Representações sociais.

E-mail: cristienecarvalho@gmail.com.

Maria Isabel Antunes-Rocha é graduada em Psicologia pela Universidade Federal de Minas Gerais, tem Mestrado em Psicologia Social e Doutorado em Educação pela Universidade Federal de Minas Gerais. É Pós Doutora em Educação do Campo pela Universidade Estadual de Presidente Prudente. É Professora Titular na Universidade Federal de Minas Gerais. Desenvolve ações de ensino, extensão e pesquisa nas áreas de Formação e Prática Docente, Educação do Campo e Teoria das Representações Sociais com foco nas Representações Sociais em Movimento.

E-mail: isabelantunes@ufmg.br. 